\title{
Hacia la comprensión de la naturaleza transnacional de las audiencias televisivas: Imaginarios, desterritorialización, hibridación, globalización*
}

\author{
Manuel Ignacio González Bernal* \\ Sergio Roncallo-Dow ${ }^{* \star *}$
}

Recibido: 2014-11-26 - Aprobado por pares: 2015-01-05

Enviado a pares: 2014-11-29 - Aceptado: 2015-02-02

\section{Resumen}

El presente texto propone repensar el carácter trasnacional de la audiencia televisiva, asumiendo que este excede la circunstancia particular de los migrantes y que debido a la globalización de la economía y a la digitalización de la comunicación se instala en la naturaleza misma de los procesos de comunicación. Así, en la primera parte del presente artículo se propondrá una conceptualización de lo trasnacional, aplicado a las audiencias, y en la segunda parte se desarrollará el argumento de que este carácter trasnacional se origina en el desarrollo y masificación de la tecnología digital y en los procesos de globalización de la economía, que han permitido la consolidación de corporaciones transnacionales de medios. En ese sentido la trasnacionalidad de las audiencias sobrepasa circunstancias puntuales ligadas con las migraciones y se instala en la naturaleza misma de la comunicación que se desarrolla hoy en la sociedad.

Palabras clave: Audiencias, Televisión, Imaginarios, desterritorialización, hibridación, globalización

* Este artículo hace parte de la reflexión teórica del proyecto de investigación Narrativas, formatos y audiencias para el Canal RCN, registrado ante la Dirección de Investigación de la Universidad de La Sabana bajo el código COM 68-2014 y cofinanciado entre el Canal RCN y la Facultad de Comunicación de la Universidad de La Sabana.

** Profesor asistente de la Facultad de Comunicación de la Universidad de La Sabana, Chía, Colombia. Director del Grupo de Investigación Observatorio de Medios. Correo electrónico manuel.gonzalez@unisabana. edu.co

*** Profesor asociado de la Facultad de Comunicación de la Universidad de La Sabana, Chía, Colombia. Investigador del Grupo Cultura Audiovisual. Correo electrónico sergiord@unisabana.edu.co 


\title{
Toward a Comprehension of Television Audiences Transnational Nature Imaginaries, Desterritorialization, Hybridation, Globalization
}

\begin{abstract}
This text proposes a second thought to television audience transnational nature assuming that this exceeds a specific circumstance of migrants and that due to economy globalization of communication it installs on the nature of communication processes. In the first part, a conceptualization of what is transnational applied to audiences will be proposed, and in the second part, the argument that this transnational character has been originated in the development and massification of digital technology and the processes of economy globalization which have allowed the consolidation of media translational corporations is developed. In this sense, transnationality of audiences exceeds specific circumstances linked to migrations and is installed on the nature of communication developed in society..
\end{abstract}

Key words: Audiences, Television, Imaginaries, desterritorialization, hybridation, globalization 


\section{Introducción}

Después de casi un siglo de investigación y desarrollo de conocimiento sobre las audiencias se podría pensar que es escaso lo nuevo que hay por decir al respecto, sin embargo, como pocos, el campo de la comunicación día a día experimenta cambios profundos que obligan a revisar definiciones y rediseñar categorías de análisis. Como lo indica Donsbach (2006, p. 437) la comunicación, como campo de investigación, ha visto el mayor crecimiento de probablemente todos los campos académicos en los últimos treinta años. Uno de los argumentos que el autor emplea para sustentar su afirmación es que el tiempo invertido por las audiencias en consumir los productos de los medios crece año a año, entre otros motivos, debido a la importancia que los contenidos de entretenimiento e información tienen para los individuos de hoy, a lo cual se podría sumar el crecimiento en la oferta proveniente de corporaciones de medios regionales, nacionales, y globales.

La reflexión de Donsbach no se reduce a un asunto de tiempo, sino que pone en evidencia una realidad que es central para comprender la dinámica de la comunicación hoy: en diferentes espacios, con intensidades diversas, a través de diferentes dispositivos y por motivos variados las personas asumen el rol de ser miembros de la audiencia.

En este sentido, las preguntas que posibilitan el análisis de las audiencias se multiplican y las visiones tradicionales que interpretaban a los consumidores de medios de comunicación como entes pasivos, fácilmente ubicables en tiempo y espacio, vulnerables al poder de significación de los contenidos, se quedan cortas. Así, surgen nuevas perspectivas de análisis ancladas en las múltiples y complejas realidades de los sujetos que hacen parte de la audiencia y en la realidad cambiante de los procesos de comunicación.

El carácter transnacional de la comunicación es uno de esos lugares desde donde es posible y necesario conceptualizar la formación y analizar el comportamiento de las audiencias. Moreno (2010, p. 58) sugiere cómo hasta hace unos años se pensaba en las audiencias como un constructo análogo a la población, la nación o el país, lo cual se veía reflejado en la forma en que los jefes de Estado utilizaban la televisión para dar informes de Gobierno o en el momento de asumir el poder. Esta práctica, común tanto en sistemas democráticos como en regímenes autoritarios, ya no se adecúa a la realidad comunicativa de hoy, en donde los mensajes no están autocontenidos dentro de fronteras geográficas, o en donde los ciudadanos realizan su consumo estando o no dentro del territorio nacional.

Chalaby $(2005$, p. 1) nos recuerda que la televisión fue central para el desarrollo de proyectos de identidad nacional en diferentes países y que ninguna otra institución jugó un papel tan determinante en dichos procesos. Sin embargo, afirma el autor, la relación cercana entre televisión y nación se ha desmoronado en las últimas dos décadas, debido a numerosos y variados motivos, dentro de los cuales tal vez el más potente es la emergencia de los canales de televisión transfronterizos (cross-border TV channels), que han permitido romper los vínculos directos entre territorialidad, carácter nacional y procesos de comunicación. 
Esta cambiante relación entre televisión y nación es una consecuencia, dentro de muchas otras, de las profundas transformaciones que ha tenido la comunicación debido al desarrollo de la digitalización y a la globalización de la economía, fenómenos que, a su vez, han facilitado la consolidación de conglomerados de medios, muchos de los cuales tienen alcance trasnacional o global. En este ambiente, la lógica implícita en la producción y distribución de productos mediáticos se ha transformado. Hoy los productos no se hacen pensando únicamente en un público nacional, sino que crecientemente se piensa en la audiencia trasnacional, aquella situada fuera de su país de origen, pero también la que estando en él accede a productos provenientes de otros contextos, mientras que sigue consumiendo contenidos marcadamente locales.

Para algunos autores, la audiencia trasnacional está ligada exclusivamente al fenómeno de las migraciones. En ese sentido Moreno (2010, p. 51) afirma que aunque pareciera que todo ha sido escrito en relación con la audiencia, todavía quedan fenómenos por conceptualizar, entre ellos la cuestión de la audiencia transnacional, definida por él como "las comunidades -valga la redundancia- transnacionales formadas por inmigrantes y los círculos de interacción que estos mantienen en sus países de origen y destino". El autor estima que el estudio de este concepto requiere de una fusión entre los estudios sobre transnacionalismo y el análisis cualitativo de la recepción.

\section{Las audiencias transnacionales}

Para abordar el fenómeno de la audiencia trasnacional resulta útil dar un vistazo al concepto mismo de transnacionalización o de transnacionalismo, el cual se ha usado indistintamente en ámbitos como el político, el económico, el educativo, etc. Kearney (1995, p. 548) al respecto menciona que lo transnacional hace referencia a dinámicas de primer orden entre dos o más Estados-nación específicos, por lo que el concepto de nación es relevante, incluso más que el prefijo trans, que normalmente es usado para dar a entender que una actividad se extiende más allá de las fronteras geográficas de un Estado. En este sentido el término trasnacional, rescatando lo nacional que existe en él, no deja de lado elementos como el territorio y las características sociales y culturales de las naciones afectadas.

Por su parte, Faist (2000) sugiere que el concepto de trasnacional cubre diversos niveles como la formación de pequeños grupos trasnacionales, los circuitos trasnacionales - donde cabe ubicar la acción de las corporaciones de medios-y las comunidades trasnacionales, cada uno de los cuales es caracterizado por un mecanismo primario de integración: la reciprocidad en los grupos, el intercambio en los circuitos y la solidaridad en las comunidades. La conceptualización de la transnacionalización, a través de estos niveles, permite ampliar la mirada sobre el fenómeno para entender que en las actuales condiciones de la vida social lo trasnacional no proviene exclusivamente de las grandes corporaciones o de los gobiernos nacionales, sino que también hay posibilidades de convertir acciones concretas de sujetos individuales en iniciativas trasnacionales. 
Faist muestra cómo existen marcadas diferencias entre globalización y transnacionalización. Inicialmente la transnacionalización se superpone con la globalización, pero tiene un alcance más limitado que ella. Mientras que el proceso global está ampliamente descentrado de los Estados nación y de los territorios, por lo tanto toma lugar en el contexto mundial, el proceso trasnacional está anclado en y se extiende a dos o más Estados-nación, involucrando actores propios.

\subsection{Algunas breves anotaciones sobre los imaginarios de nación}

El crecimiento de las migraciones, como consecuencia de otras realidades sociales, se ha convertido en un aspecto facilitador de los procesos de transnacionalización. Desde la perspectiva de los migrantes, Moreno (2009, p. 17) aporta una definición canónica de transnacionalismo y que podría ser pensada desde:

[l]os procesos a través de los cuales los inmigrantes forjan y sostienen relaciones sociales multi-filares que se enlazan a sus sociedades de origen y de asentamiento. Llamamos a estos procesos de transnacionalismo, para destacar el hecho de que muchos de los inmigrantes de hoy construyen campos sociales que cruzan las fronteras geográficas, culturales y políticas. Aquellos inmigrantes que desarrollan y mantienen múltiples relaciones - familiares, económicas, sociales, organizacionales, religiosas y políticas - más que las que abarcan las fronteras los llamamos "transmigrantes" (Basch, Glick Schiller, Szanton Blanc: 1994: 7)'1.

Hoy en día los inmigrantes no están aislados, debido a que tienen la posibilidad de viajar a su lugar de origen o de mantener el contacto con familiares y amigos, gracias al desarrollo y masificación de las tecnologías de la comunicación. Adicionalmente, en sus lugares de asentamiento crean espacios y usan recursos, como los medios de comunicación, a través de los cuales sostienen relaciones sociales que les permiten conservar su identidad y mantener el sentido de pertenencia a sus comunidades de origen (Moreno, 2010, p. 52).

Desde la perspectiva de los migrantes, la aparición de las audiencias trasnacionales hace referencia a aquellas personas que ubican su residencia en un lugar geográficamente diferente al de su nacimiento, y que terminan por demandar productos mediáticos afines a su identidad y su cultura, con lo cual estimulan una oferta de contenidos específicos para audiencias extranjeras, sin olvidar que de cierto modo también hacen parte de la audiencia local.

\section{Al respecto Ekwo (2011, p. 4) sostiene que}

Hoy en día, la comunidad de la Diáspora en particular los migrantes, los refugiados, los forasteros, exiliados, expatriados y en especial a todas las personas que viven fuera de sus países de origen, nativos o imaginarios, se han convertido en importantes consumidores de la oferta mediática y hacen uso de los medios de comunicación de diferentes maneras. Por ello, no es sorprendente que algunos inmigrantes emprendedores establezcan redes noticiosas e instituciones (meditáticas) que se dedican a la producción y distribución de contenidos que reflejen sus experiencias culturales y sus propias

1 Traducción de los autores 
identidades. Esta relación fluida y de adaptación entres los medios de comunicación y personas a nivel global tiene implicaciones para los medios de comunicación y las culturas nacionales, la cooperación internacional y la solidaridad, el buen gobierno y la evolución de la ciudadanía global².

Así las cosas, es clave recordar que la idea de la nación, en medio de su carácter aparentemente abstracto, trae consigo múltiples problemas en términos de una forma de ser asida epistemológicamente. Como lo ha recordado Hopenhayn (2001) el proceso de concreción de lo identitario no pasa solo por la idea del arraigo sino, a la vez, por la del desarraigo. En un mundo en el que parece primar el tiempo real sobre la temporalidad extensa (Virilio, 1999) se da un movimiento paradójico en el que pensar lo nacional, por ejemplo, supone otros modos de abordaje. El sujeto aparece, cada vez más, como un actor desanclado que más allá de un territorio habita una suerte de espacio tercero que se presenta ya no bajo la forma del territorio sino del imaginario. ¿Podemos habitar un imaginario?

Una primera idea parecería llevarnos por el terreno frágil del aparente desanclaje posmoderno y sugerir la idea de un sujeto abyecto que no habitaría más que sus propias fantasmagorías. Empero, la necesidad insoslayable de lo identitario permite pensar este imaginario en términos de flujos, de constantes movimientos que desanclan la idea de la identidad de la de la pura pertenencia a un lugar. En efecto, nos encontramos aquí de frente con lo que Anderson (1993) ha llamado las comunidades imaginadas y que constituyen, en efecto, una idea mucho más rendidora para pensar la idea misma de nación en tanto nos remiten a una idea anclada a la del relato, si se quiere a la del invento discursivo. Anderson nos pone de frente con una idea que quizá resulte incómoda: las comunidades son un invento al que acudimos en busca de la seguridad ontológica, un invento que nos ayuda a dar nombre a lo desconocido, la comunidad imaginada apela a esa necesidad que tenemos de sentirnos en casa. Recuerda el autor:

[Esta comunidad] es imaginada porque aun los miembros de la nación más pequeña no conocerán jamás a la mayoría de sus compatriotas, no los verán ni oirán siquiera hablar de ellos, pero en la mente de cada uno vive la imagen de su comunión. Renan se refirió a esta imagen, en su estilo afablemente ambiguo, cuando escribió: "Or l'essence d'une nation est que tous les individus aient beaucoup de choses en commun, et aussi que tous aient oublié bien des choses" ${ }^{3 \prime(B}$. Anderson, 1993, p. 23)

La comunidad imaginada se objetiva, entonces a partir de eso que llamamos, permítasenos aquí esta aparente redundancia, un imaginario común, esto es, sobre todo un conjunto de referentes entre los que, otrora, habríamos incluido (con Anderson) la existencia del territorio común. En nuestra apuesta por la construcción de una idea de las audiencias transnacionales lo que proponemos es la fractura del argumento del irlandés y pensar la idea de nación allende la idea del territorio y ubicarla más bien dentro de las construcciones que, si bien, colectivas, deben inscribirse dentro de nuevos regímenes de

2 Traducción de los autores

3 "Pero la esencia de una nación es que todas las personas tienen muchas cosas en común, y también de que se han olvidado de muchas cosas." Traducción de los autores. 
circulación de signos. La idea que subyace este punto es, precisamente, la de desterritorialización y abre la necesidad de nuevos anclajes categoriales. Pensar la audiencia transnacional significa entonces pensar el modo en el que los diversos imaginarios de nación se entretejen y dan origen a un cierto tipo de sujetos-receptores-descodificadores que, por supuesto, suponen un reto metodológico en el momento de emprender una análisis de audiencias, pues cada individuo es dueño de unos códigos interpretativos y discursivos que ha adquirido a lo largo de su experiencia vital y que son su punto de partida para descodificar los mensajes mediáticos a los que se enfrenta cotidianamente pero que, en nuestro caso, se presentarían como un enjambre de imaginarios y de re-significaciones que no resultarían fáciles de asir.

A esto cabe sumar que el proceso de descodificación no es siempre consciente y reflexivo, tiene también que ver con las competencias, códigos aprendidos, mensajes ya recibidos y condiciones contextuales -subculturas, por ejemplo- de cada sujeto. El sujeto que descodifica no hace parte, ya lo sabemos, de una audiencia indiferenciada; por el contrario, la audiencia es una compleja estructura de grupos y subculturas que se superponen y en los cuales se mueven los individuos. Así pues, las descodificaciones individuales de los mensajes pasan por las herramientas semióticas que otorgan a cada individuo su pertenencia a determinado grupo social o subcultura pero esta no es, de ninguna manera, la variable única y determinante del proceso. En el sujeto descodificador tienen igual importancia, en el proceso de interpretación de mensajes, el contexto y las competencias y condiciones individuales del sujeto. El sentido de un texto o mensaje mediático no es otra cosa que el producto de la interacción entre los códigos que ya habitaban en los diversos sectores de la audiencia y los nuevos que aporta el texto. "Se trata siempre de que una posición social, más posiciones discursivas particulares, produce lecturas específicas que están estructuradas porque la estructura de acceso a los diferentes discursos está determinada por la posición social" (Morley, 1996, p. 171). A esto añadiríamos: se trata de los múltiples lugares que se habitan hoy en tiempos de flujos.

\section{Comunicando transnacionalmente}

El concepto de lo trasnacional implica una suerte de giro espacial y cultural en el modo de concebir las audiencias. En efecto, lo transnacional parece ser una idea que se aplica sin dificultad a diferentes realidades sociales, que tienen en común un ámbito de acción, un espacio-otro, que sobrepasa los límites de un país o una sociedad nacional. En palabras de Müller-Mahn (2005, p. 29) "El concepto de espacio social transnacional utiliza el "espacio "como una metáfora de las redes sociales, siguiendo a Bourdieu. En consecuencia, el espacio social transnacional es considerado como una estructura de referencia para los posicionamientos sociales, más allá del contexto del Estado-nación y la sociedad nacional" ${ }^{4}$.

Siguiendo esta línea de reflexión, en el presente texto se usará el concepto de "trasnacional" como aquello que se extiende a través de varias naciones, a través de múltiples

4 Traducción de los autores. 
imaginarios y que se re-significa en su carácter intrínsecamente híbrido. Al aplicar esta mirada al análisis de las audiencias, por ende, se entenderá que la audiencia trasnacional es aquella que se extiende a varias territorialidades y que estando geográficamente dispersa se puede conceptualizar como una. Acerquémonos brevemente a las ideas de desterritorialización para entender mejor este punto y comprender cómo, además del giro espacial, el concepto entraña, a la vez, un giro cultural.

En un mundo en el que priman la velocidad y el tiempo real, en el sentido en el que lo identifica Virilio (1999), podemos afirmar que nos encontramos ante lo que llamarían Morley (1996) y Maffesoli (2005), culturas nómadas, errantes. En América Latina, por ejemplo, la inmensa mayoría de la población ya no es campesina, pero tampoco se puede definir como urbana, desencadenando una re-significación de lo rural y también de lo urbano hacia el descentramiento cultural, hacia la desnacionalización. Las nuevas generaciones de latinoamericanos, de colombianos, crecen con referentes culturales ya no ceñidos al territorio ni a los tradicionales del país. La desterritorialización ha ubicado los referentes de vida, los modelos de acción, los procesos de construcción de identidades más allá de las fronteras nacionales. No significa esto que se pierdan las temáticas y las cotidianidades locales, pero sí que estas se narren y se referencien a partir de los modelos trasnacionales. La desterritorialización espacial es acompañada de un proceso de reterritorialización en los referentes comunes, en este caso de lo mediático, que traspasan las fronteras de lo local.

Paralelamente podemos pensar en la hibridación como rasgo fundante de nuestro presente (y nuestro pasado, por supuesto). Los meta-relatos de nuestras historias nacionales y, en esta medida, de nuestras políticas y nociones de cultura, nos han enseñado que 'una cultura auténtica es cultura pura, una cultura que no se mezcla' (Martín-Barbero, 1995, p. 146). Bajo esta lógica se inscribió hasta hace algún tiempo el imaginario de lo que significa ser latinoamericano o colombiano, de las identidades homogéneas a partir de la diferencia con lo otro, con el establecimiento claro de una frontera, territorial o cultural. Hoy en día sabemos que la historia de nuestro continente es la historia de luchas, enfrentamientos e hibridaciones.

En palabras de García Canclini, Latinoamérica habría llegado a la Posmodernidad antes que pasar por la Modernidad en la medida en que su historia y su esencia misma son un gran collage, una superposición sincrética de fragmentos, una estructura de palimpsesto (citado en Martín-Barbero, 1995, p. 146).

Así pues, solo en la medida en que reconozcamos nuestra esencia híbrida y las condiciones particulares de modernización e inserción en la dinámica de las industrias culturales, de la cultura visual, comprenderemos por qué en nuestras ciudades hay culturas nuevas en las cuales los medios no son simplemente canales de transmisión de una cultura ya hecha sino de gestación misma de las nuevas formas culturales en tanto la tecnología de comunicación se ha convertido en el canal de interacción e hibridación con las formas locales del resto del mundo. 
La audiencia trasnacional representa el público desterritorializado y muchas veces híbrido que tiene acceso y consume los contenidos de un medio de comunicación desde dos o más naciones en las que tenga la posibilidad de hacerlo. La posibilidad hace referencia a las condiciones técnicas, económicas y políticas que facilitan o limitan el acceso a los productos difundidos por los medios. Hoy asistimos a formas desancladas de errancias y nomadismos que como lo señala Echeverría (1999) pasan por lo rural, lo urbano y lo electrónico/ digital (sobre este último punto volveremos más adelante). Esto, que recuerda inmediatamente la idea ya clásica hoy de tercer espacio, resulta clave para entender la idea del giro cultural en el momento de pensar la audiencia transnacional: hibridación y desterritorialización.

Pensemos cómo, en este sentido, los inmigrantes mexicanos en los Estados Unidos, que consumen productos de comunicación distribuidos específicamente para ellos o que desde su residencia acceden a los canales locales de México constituyen una audiencia tan trasnacional como los mexicanos que estando en su territorio nacional consumen activamente los productos de cadenas internacionales como Sony Entertainment Televisión, Discovery Channel o NAT GEO.

Chalaby afirma que los canales de televisión transfronterizos (Cross-border TV Channels), como los mencionados, son en buena medida responsables de la transnacionalización de las audiencias y a pesar de su amplísima diversidad son agrupados bajo la categoría genérica de trasnacionales. Para el autor

[los] canales internacionales cubren todos los nichos televisivos posibles en el mercado, que van desde el deporte hasta el cine y la religión pasando por el entretenimiento para adultos. Por encima de todo, presentan varios tipos de transnacionalidad y difieren en cuanto a la propiedad, los objetivos, el alcance, la estrategia transfronteriza, los recursos y el público (Chalaby, 2005, p. 2).

Las grandes corporaciones que poseen canales trasnacionales de televisión, los medios locales e incluso los pequeños productores que distribuyen contenidos a través de YouTube u otras plataformas digitales enfrentan el reto de comunicar trasnacionalmente, lo cual de entrada implica vencer viejas miradas que ignoran la naturaleza actual de la comunicación. Basta recordar el discurso que se ha desarrollado desde algunos sectores académicos y políticos, que han interpretado el contenido mediático extranjero como enemigo de la identidad y la cultura de una nación.

Controvirtiendo esa clase de discursos Jenkins (2013) pone de ejemplo el caso de Makmende, un superhéroe que aparece en algunos videoclips de Just a Band, una agrupación musical de Kenia. Esta banda se ha caracterizados, entre otros motivos, por desarrollar y difundir con éxito sus propias producciones audiovisuales, apoyándose en una estrategia de comunicación digital que incluye fuerte presencia en blogs, páginas web y redes sociales.

$5 \quad$ Traducción de los autores. 
Para el autor, Makmende es el reflejo de las formas en que el mestizaje de culturas se ha convertido en alternativa de emancipación para aquellos que buscan escapar del aislamiento cultural y entrar en una conversación transnacional más grande. Sobre este personaje Jenkins considera que:

Makmende no es puramente africano ni puramente americano: la piedra angular es un compuesto cultural, cuya identidad híbrida y remezclada está marcada por una serie de pasos (osmóticos) de frontera, momentos en los que dos culturas - o tal vez más- se tocan entre sí a través de distancias geopolíticas. La impureza cultural de Makmende hace de él un ejemplo particularmente poderoso de la forma en que el contenido se desarrolla y se distribuye en la fase actual de la globalización6 (Jenkins et al., 2013, p. 262).

Esta clase de mensajes o productos no son solo heterogéneos en su diseño y producción; también lo son en la interpretación que las audiencias hacen de ellos. En un ambiente de comunicación trasnacional, los productos viajan y son consumidos en contextos culturales diversos, con lo cual se afirma la idea de que sobre ellos se producen diferentes significados y sentidos. Esto implica, además de abandonar las concepciones apocalípticas sobre la homogeneización de la cultura, la necesidad de incluir en el análisis de la comunicación categorías como la participación, la colaboración, la interacción, etc., todas ellas vinculadas a la forma en que las audiencias trasnacionales realizan su consumo de mensajes.

Por otra parte, las audiencias, a través de sus patrones de exposición, también han evidenciado en innumerables oportunidades la importancia que para ellas tiene la producción local, lo cual complejiza aún más el análisis y la interpretación de su carácter trasnacional. Con su fidelidad a los productos locales, pero a la vez con un creciente interés en los formatos y el contenido internacional, cargado de diversidad cultural, han presionado el desarrollo de prácticas de localización del contenido, como las adaptaciones.

Un buen ejemplo de ello es el éxito obtenido por el seriado A corazón abierto, la adaptación colombiana de Gray’s Anatomy, que a la fecha es el producto con mayor rating promedio en toda la historia de la televisión privada en Colombia ${ }^{7}$. De esta serie novelada el Canal RCN realizó dos temporadas, las cuales se han emitido con éxito en varios países de la región.

Un caso a la inversa, también digno de ser tenido en cuenta, es el de la telenovela colombiana Yo soy Betty la fea, que, además de haber tenido un éxito rotundo en el ámbito nacional, se emitió en más de cien países, se dobló a 15 idiomas y se adaptó 22 veces a las condiciones culturales de ese número de naciones. Yo soy Betty la fea pone en evidencia la forma en que un producto exitoso dentro de un contexto estrictamente local puede

6 Traducción de los autores. Texto entre paréntesis de los autores.

7 Colombia inició la era de la televisión privada con la inauguración de los canales RCN y Caracol el 10 de julio de 1998, luego de un proceso de licitación pública. Si bien esta fue la primera vez en que entraron en funcionamiento canales completamente no estatales, la empresa privada ya había incursionado en la industria de la televisión, a través de productoras que se encargaban de programar franjas en canales manejados por el estado. 
llegar a triunfar en otros mercados de audiencias, a pesar de no provenir de los grandes centros de producción y distribución de contenidos como los de los Estados Unidos.

Así, comprender la naturaleza trasnacional de las audiencias supone pensar en procesos de comunicación favorecidos por el desarrollo de la tecnología digital, por los diferentes niveles de alcance geográfico de las corporaciones mediáticas y por la amplia diversidad cultural de las personas que finalmente reciben e interactúan con los productos de información y de entretenimiento. Reconocer la transnacionalidad de la audiencia implica no olvidar que esta lleva consigo características que son propias de la cultura de las dos o más naciones de donde provienen sus miembros, su identidad, su lengua, los usos y costumbres de sus gentes, sus rasgos religiosos, etc., lo cual refuerza la idea de que el componente local del proceso comunicativo no desaparece, sino que se complementa y se hace compleja.

Para Jenkins, el carácter trasnacional de las audiencias proviene de la misma transnacionalidad del contenido y de los procesos de comunicación. Según el autor:

El contenido de los medios transnacionales a veces llega a través de la puerta principal, distribuido por intereses comerciales (grandes y pequeños) de quienes buscan expandir mercados. Otras veces, se llega a través de la puerta de atrás, a través de los esfuerzos de los piratas que tratan de sacar provecho de los medios de comunicación producidos por otros, a través de los inmigrantes que tratan de mantener el contacto con las culturas que han dejado atrás, o a través de las audiencias que buscan expandir su acceso a la diversidad cultural del mundo (Jenkins et al., 2013, p. 260).

Tal como se mencionó anteriormente, el carácter transnacional de la comunicación y de las audiencias no es una característica innata en ellas, sino que tiene sus bases en dos fenómenos propios del siglo XX: el proceso de globalización de la economía y el desarrollo de la tecnología digital, que ha generado una revolución en las formas de producir, distribuir e interactuar con los productos de los medios.

\section{Digitalización y transnacionalización de las audiencias}

La digitalización de la comunicación es entendida como el proceso de cambio en la producción, almacenamiento, distribución y consumo de contenidos informativos o de entretenimiento, pasando de un soporte análogo a uno digital. La característica más importante de la digitalización es que los productos pasan de ser objetos físicos a ser codificaciones binarias electrónicas, a las que se accede a través de una amplia variedad de dispositivos.

McQuail (2010, p. 555) menciona que digitalización es un término general que describe el procesamiento, almacenamiento y transmisión computarizada de datos, empleando el código binario, y como tal es la base de la convergencia de los medios. Para el autor, un caso por el que hoy la digitalización es mejor conocida en el mundo es el reemplazo de las señales de transmisión de televisión analógicas por las digitales, lo cual permite un

8 Traducción de los autores. 
aumento en el potencial de la capacidad del canal y en el alcance de la interactividad. Este proceso de cambio ya se ha vivido en algunos países como los Estados Unidos y parte de Europa, mientras que en otros hasta ahora se está iniciando.

Para Castells (2008, p. 400) la digitalización equivale a lo que en su momento fue la invención del alfabeto, que proporcionó la infraestructura mental para el conocimiento al hacer posible la comunicación acumulativa. Menciona este autor que hoy en día es la digitalización la que hace posible la fácil integración de diferentes tipos y modalidades de información en el interior del sistema de medios, lo cual implica otra revolución.

Afirma Picard (2011, p. 6) que el proceso de digitalización de la comunicación empezó hace más de cinco décadas, inicialmente en la producción de medios impresos y luego pasó al ámbito de los medios audiovisuales. Su implementación redujo costos y tiempos de producción y proporcionó mayor capacidad y eficiencia en el almacenamiento de contenidos. Todo esto repercutió en la mayor producción, distribución y consumo de medios por parte de las audiencias.

Para este autor la digitalización no produce nuevos medios de comunicación, sino que transforma los procesos típicos en los ya existentes y, sobre todo, altera la distribución y la producción de significados por parte de las audiencias. Este no es un proceso exclusivo de los medios, sino que hace parte de transformaciones mayores que día a día se producen en todo tipo de organizaciones y actividades, gracias a los avances en los campos de la computación y las telecomunicaciones.

Uno de los procesos en los que se materializa el alcance de la digitalización es en el desarrollo de la convergencia. Para Jenkis (2006, p. 14) la convergencia, hace referencia al flujo de contenido a través de múltiples plataformas de medios, a la cooperación entre los diversos sectores de los medios y al comportamiento migratorio de las audiencias, que van a cualquier lugar en busca de las experiencias de entretenimiento que desean, lo cual implica, entre otras cosas, que se favorece el ingreso de contenidos extranjeros en la composición del consumo mediático.

Orozco (2008) al respecto menciona que la convergencia, sugerida como uno de los fenómenos característicos de la época de grandes cambios en la comunicación, inaugura una etapa de multiplicación de la oferta de contenidos, lo cual conlleva a la infidelidad de las audiencias con las pantallas y los productos. Afirma el autor que con la convergencia se amplifican como nunca las combinaciones de referentes mediáticos y se potencian las posibilidades expresivas y creativas de recepción y emisión de productores y audiencias.

Para Picard (2011, p. 20) la consecuencia más importante de la digitalización para las audiencias es que, en este ambiente, deben encarar una sobre oferta de contenidos abrumadora, pues a la tradicional producción nacional de información y entretenimiento se suman los productos televisivos que llegan a través del cable o el satélite, los contenidos multimedia que están en el Internet y, en algunos casos, la ampliación de la distribución de publicaciones periódicas impresas provenientes de diferentes países. 
En este sentido la interacción de las audiencias con los medios y sus mensajes deja de enmarcarse en el ambiente local, los referentes culturales del público se multiplican, las producciones adquirieren mayor alcance y las posibilidades de negocio crecen de manera exponencial debido a la ampliación de los mercados. En este sentido la digitalización también está en la base de la transformación que han sufrido las empresas de medios hasta convertirse algunas de ellas en corporaciones globales, asunto que se abordará en el siguiente apartado.

Así, entre otros motivos, gracias a los procesos de digitalización la transnacionalización de la comunicación hoy es una realidad palpable, no solo desde la naturaleza de las corporaciones que poseen los medios, sino también desde las características de los mensajes y desde la visión que se tiene de las audiencias. Incluso, las empresas de medios que operan en un ámbito estrictamente local requieren para el desarrollo de sus estrategias corporativas tener siempre presente que están compitiendo con jugadores regionales y globales interesados en captar la atención de las mismas personas.

De lo anterior se concluye que las audiencias contemporáneas se desarrollan bajo una lógica de comunicación transformada por la masificación de la tecnología digital. La revolución generada por la digitalización de la comunicación actualmente permite a las empresas de medios, entre muchas otras cosas, la producción, almacenamiento, reproducción y difusión de contenidos a escalas mayores y con costos más bajos que en la era de la comunicación analógica, con lo cual se amplían las posibilidades de llegar con un producto a consumidores geográficamente o culturalmente distantes.

Para Ekwo (2011, p. 7) la combinación entre globalización y desarrollo de tecnologías digitales está reformando la manera en que los medios de comunicación interactúan y se conectan con las audiencias, pues en la era de la convergencia de medios crece el acceso a la producción y distribución de contenidos, lo cual amplía el potencial para el diálogo intercultural entre diferentes regiones del mundo. Para la autora un ejemplo de ello es el ambiente digital de los Estados Unidos, bajo el cual operan la mayoría de los medios de comunicación de diásporas y en el que los consumidores se han convertido en participantes críticos dentro de los procesos de creación y difusión de contenidos. Menciona Ekwo que esta tendencia tiene la potencialidad de promover la pluralidad de voces y los intercambios interactivos entre audiencias de diferentes orígenes, incluyendo a los miembros más desfavorecidos de la sociedad, con lo cual se favorecen los procesos de formación de opinión pública en torno a diferentes temas.

Así, los procesos de digitalización de la comunicación posibilitan que las audiencias adquieran unos rasgos específicos distintivos, que las convierten en actoras reales y vivas del ambiente mediático. Gracias a estos rasgos, las audiencias definen su exposición a los medios, seleccionan dentro de las muchas opciones de productos, interactúan, producen contenidos, son autónomas en su comportamiento mediático, se mueven dentro del contenido y a través de las diferentes plataformas que existen para accederlo, producen y comparten significados, no son simplemente receptoras sino que se han convertido en iniciadoras de las dinámicas de comunicación social, entre otras características. 
Sobre este último punto se fundamenta otro de los grandes aportes de la digitalización a la transnacionalización de las audiencias, pues, además de facilitar el crecimiento y expansión de las corporaciones de medios y sus contenidos, también ha permitido que los usuarios asuman diferentes niveles de compromiso y de acción frente a su consumo mediático. Dentro de los niveles de acción resulta relevante mencionar el tema de la cultura participativa (Jenkins, 1992) que hace referencia a la producción cultural y a la interacción social que se da entre los miembros más activos de una audiencia. Esta participación activa ha facilitado que los productos se difundan a través de las redes sociales y de otros espacios y mecanismos de comunicación y en torno a ellos se erijan verdaderas comunidades trasnacionales de seguidores o incluso de detractores. El mismo Jenkins define la cultura participativa como:

[...] la producción cultural y las interacciones sociales de las comunidades de fans, que buscan, inicialmente, una forma de diferenciar las actividades de los fans de las de otros tipos de espectadores. A medida que el concepto ha evolucionado, ahora se refiere a una gama de diferentes modos de despliegue de producción y distribución para servir a sus intereses colectivos; es así como varios estudiosos han vinculado el fandom a un discurso más amplio sobre la participación en y a través de los medios de comunicación ${ }^{9}$ (Jenkins et al., 2013, p. 2).

Una evolución reciente de la cultura participativa como concepto la desarrolla el mismo autor bajo el concepto de spreadability, el cual se refiere al potencial técnico y cultural que tienen las audiencias para compartir contenidos, de acuerdo con sus propios propósitos, algunas veces con el permiso de los propietarios y otras en contra de sus deseos.

La spreadability de los mensajes, como característica del ambiente mediático actual, se sitúa como uno de los pilares del carácter transnacional de las audiencias, pues les permite a sus miembros apropiar los productos, valorarlos, modificarlos, incrustarlos en otros contextos, etc., pero sobre todo le permite a las audiencias compartir su consumo dentro y fuera de las fronteras geográficas de su país. Así los fans que antes se organizaban en clubes nacionales que seguían y promovían la carrera de cantantes o actores, hoy se constituyen en verdaderas comunidades trasnacionales que funcionan a través de redes sociales y que logran importantes niveles de visibilidad y, por lo tanto, apropian un alto nivel de influencia.

En síntesis, los aportes de la digitalización a la transnacionalización de las audiencias podrían resumirse en tres asuntos principales. El primero es que permite la reproducción y difusión de contenidos a escalas mayores, con costos más bajos que en la era de la comunicación analógica. Esto lleva al segundo asunto, que es la generación de un ambiente de sobre oferta de contenidos, que tiene como consecuencia la transformación del consumo y a la multiplicación de referentes culturales para las personas. El tercer aporte es que la digitalización permite a las audiencias tener un papel más activo, les facilita buscar y acceder al contenido que desean, interactuar con los productores y con otros consumidores de medios, valorar públicamente los productos, difundirlos y, en últimas,

9 Traducción de los autores. 
hacer parte de una cultura participativa que facilita la spreadability de los mensajes y, por lo tanto, la transnacionalización de la comunicación desde los usuarios.

\section{Globalización y transnacionalización de las audiencias}

La comunicación se ha convertido en una de las facetas más conocidas de la globalización, que viene desarrollándose en el mundo desde hace varias décadas. Sin entrar a analizar en detalle el fenómeno de la globalización, pues no es el objetivo de este trabajo, se puede decir que sus consecuencias en el campo de las comunicaciones sobrepasan el ámbito económico y se concentran con fuerza en los ámbitos cultural y social, pues tocan aspectos tan relevantes como la identidad de los pueblos o sus referentes educativos, entre otros. Sin embargo, en lo económico está parte de la motivación de la globalización de las comunicaciones, y en este ámbito también se identifican algunas de sus consecuencias prácticas, pues los productos de los medios son bienes que se comercializan y, además, la acción de los medios dinamiza los mercados a través del influjo de la publicidad en sus receptores.

Garnham (1983, p. 16) afirma al respecto que "La televisión, como los otros medios, es en primer lugar una entidad económica que desempeña una función directamente económica en cuanto creadora de plusvalía a través de la producción de mercancías y de su intercambio, y otra función económica indirecta, mediante la publicidad, creando plusvalía en otros sectores de la producción".

Así, resulta lógico que las organizaciones que producen medios de comunicación hayan asumido una naturaleza corporativa, lo cual les ha facilitado insertarse con comodidad dentro de las lógicas económicas y empresariales propias de la globalización. Teniendo en cuenta que para la industria de los medios comerciales su principal negocio radica en cultivar audiencias que puedan ser vendidas a los anunciantes (Napoli, 2001) la globalización se convierte en un escenario más que oportuno para apalancar el crecimiento de este sector, pues facilita que haya una rotación de contenidos en diferentes regiones o países. Dicho en otras palabras, las corporaciones de medios, asumiendo las lógicas de la globalización, han logrado ampliar los campos en donde cosechan su producto.

Lo anterior no implica asumir que las audiencias se hayan globalizado, pues además de las variables tecnológicas o empresariales, el factor cultural juega un papel preponderante a la hora de entablar procesos de comunicación, lo que quiere decir que no todos los formatos o productos comunicativos trabajan de igual manera en las diferentes regiones o países del mundo. Además, en los circuitos mundiales de comunicación tampoco hay espacio equitativo para todos los participantes. Así, de acuerdo con Jenkins, resulta más preciso hablar de su transnacionalización:

Usamos el término "transnacional", en lugar del mucho más común "global", intentando reconocer la naturaleza desigual de estos flujos. (...), Mientras que los textos mediáticos se están intercambiando entre las comunidades de muchos países diversos y dispersos, también hay muchos países (especialmente en el Sur Global - gran parte de África, partes de América Latina y Asia) que aún no están en capacidad de participar 
activamente en este tipo de intercambios. Este aumento de la circulación transnacional en algunos casos amplifica la ya poderosa influencia de los productores de los países desarrollados y, en otros, refleja los esfuerzos de los productores de los medios en el mundo en desarrollo para aumentar su (a veces ya poderosa) influencia ${ }^{10}$ (Jenkins et al., 2013, p. 259).

La permanente búsqueda de eficiencias económicas, propia de las corporaciones de medios comerciales, ha llevado también al afianzamiento de prácticas como la exportación de contenidos, que ha permitido a las grandes compañías dedicadas a esta actividad entrar a competir con productos globales en mercados locales. Esta tendencia no es nueva, pues ya desde los años sesenta los distribuidores habían empezado a llevar productos realizados especialmente en los Estados Unidos a otros países. Al respecto Sinclair (2000, p. 37) menciona que la estrategia de los distribuidores en los mercados emergentes en algún momento consistió en vender productos de acuerdo con el tamaño de la red y de su capacidad monetaria. Así, el mismo programa por el que en Canadá o Australia se pagaban miles de dólares, era vendido en Tailandia por 500 dólares o en Haití por 75. Con esa estrategia de precios, en algunos países los productores locales se quedaron sin incentivos para desarrollar su propia programación.

La evolución de esta tendencia en la actualidad ha permitido que, por ejemplo, las empresas de distribución de televisión por suscripción cuenten dentro de su oferta con una programación cada vez más global. Las diferentes temporadas de Grey's Anatomy o de The Big Bang Theory, por citar dos casos vigentes y exitosos, circulan cada vez con menos tiempo de diferencia entre el gran público de los Estados Unidos, Europa, o los países en vías de desarrollo de Asía o América Latina. Asimismo, las televisiones locales compran los derechos de otras producciones y hacen adaptaciones locales de ideas globales, ahorrando en los gastos asociados al desarrollo creativo y asegurando parte del éxito en la exhibición, tal como quedó evidenciado con el caso de la adaptación colombiana de Grey's Anatomy, mencionado anteriormente.

En últimas, una de las consecuencias de la aplicación de estas lógicas económicoempresariales al ámbito de los contenidos es precisamente que la audiencia se va volviendo un ente trasnacional. Se podría pensar en una híper masificación de la audiencia, en términos de su gran amplitud, pero cada vez con más información detallada sobre su origen, preferencias, expectativas, etc., debido a la información que ellas mismas, incluso a veces sin saberlo, han proporcionado a los medios y a los anunciantes. En este sentido las audiencias trasnacionales se sitúan en un lugar central dentro de la lógica comercial imperante en el panorama de comunicación global, pues trascienden su ámbito geográficomediático natural y se proyectan como potenciales consumidores de una infinidad de bienes y servicios.

Así, la globalización está presente en la comunicación y la comunicación permite y facilita el desarrollo de los procesos de globalización. Esta relación simbiótica se materializa gracias a la formación y consolidación de conglomerados mediáticos que han expandido

10 Traducción de los autores. 
sus operaciones a lo largo y ancho del planeta y que se convierten en los actores protagónicos de la transnacionalización de la comunicación.

Appadurai (1990) hace un complejo análisis, no solo de la relación estrecha entre globalización y medios de comunicación, sino también desde otros elementos que conforman el mundo en la era global. El autor plantea cinco dimensiones, a las que él llama paisajes, que forman un marco de referencia útil para explorar las dislocaciones que se presentan en la economía cultural global: Paisaje étnico, paisaje técnico, paisaje financiero, paisaje mediático y paisaje ideológico. El autor al respecto menciona que:

La nueva economía cultural global tiene que ser entendida como un complejo y yuxtapuesto orden disyuntivo que no puede ser entendido por más tiempo en términos de modelos de centro-periferia existentes (incluso los que pudieran dar cuenta de múltiples centros y periferias). Tampoco es susceptible a los modelos simples de "dentro" y "fuera" (en términos de la teoría de la migración) o de superávit y déficit (como en los modelos tradicionales de la balanza comercial), o de los consumidores y de los productores (como en la mayoría de las teorías neo marxistas del desarrollo) (...) la complejidad de la economía global actual tiene que ver con ciertas dislocaciones fundamentales entre la economía, la cultura y la política ..." (Appadurai, 1990, p. 296).

Sugiere Appadurai que los cinco paisajes deben ser pensados como bloques con los que se construye el mundo imaginado, que no es otra cosa que los múltiples mundos construidos en la imaginación de personas concretas. Para el autor las personas viven instaladas allí y por lo tanto están en capacidad de responder y hasta de controvertir otros mundos imaginados que los rodean, como puede ser el oficial y el empresarial.

Al hablar específicamente de paisaje mediático el autor se refiere al equipamiento electrónico necesario para la producción y diseminación de mensajes. Asimismo, el paisaje mediático hace referencia a las imágenes del mundo producidas y puestas en circulación por los medios. Afirma el autor que las imágenes difundidas dependen del tipo de medio, de la forma que adopta el mensaje (género o formato), del tipo de audiencia (local o trasnacional) y, especialmente, de los intereses de los propietarios y de quienes manejan y controlan esas organizaciones.

Lo interesante de la tesis de Appadurai es que muestra que, en el contexto de la globalización, existe una profunda interrelación entre los "paisajes" que conforman la realidad de cualquier persona. Su razonamiento pone de relieve la amplísima variedad de sujetos que fluyen por el mundo, cuyas circunstancias concretas se construyen sobre determinantes tecnológicos y financieros. Esas circunstancias personales están reflejadas en y a la vez alimentadas por las imágenes que transmiten los medios de comunicación, que a su vez dependen íntimamente de la disponibilidad de la tecnología y de las visiones de mundo e ideas políticas de quienes ostentan su propiedad.

Así, la organización empresarial y la propiedad de los medios en el mundo globalizado se convierten en un aspecto central para comprender los flujos de comunicación, los tipos de mensajes, las ideologías implícitas en ellos y, por supuesto, su ámbito de difusión.

11 Traducción de los autores. 
Las corporaciones trasnacionales que poseen parte o la totalidad de los medios de comunicación más grandes e influyentes del mundo hacen parte de lo que Sklair (2002, p. 145) llama Clase Capitalista Trasnacional (CCT), concepto que hace referencia a cuatro grupos diferentes, pero estrechamente interrelacionados, que son los que ostentan el poder efectivo en el sistema global. Para el autor, mientras cada uno de estos grupos desempeña diferentes funciones, las personas que los conforman se mueven con facilidad de uno a otro, e incluso hay individuos clave que pueden pertenecer a más de un grupo a la vez. La CCT está conformada por los siguientes grupos:

- El corporativo, compuesto por aquellos que poseen y controlan las corporaciones trasnacionales.

- El estatal, del que hacen parte burócratas y políticos globalizados

- $\quad$ El técnico, que incluye a los profesionales globalizados

- El consumista, encarnado en los comerciantes y los medios de comunicación desde la publicidad.

Las corporaciones transnacionales, el primer grupo, dentro de las que se pueden incluir algunas organizaciones de medios, son pensadas por Gershon como

[...] una empresa con sede a nivel nacional y con operaciones en el extranjero en dos o más países. Una característica distintiva de la empresa transnacional (ETN) es que la toma de decisiones estratégicas y la asignación de recursos se basan en los objetivos económicos y en la mayor eficiencia sin tener mayormente en consideración las fronteras nacionales. Lo que distingue a la empresa de medios transnacional (EMTN) de otros tipos de empresas transnacionales es que el principal producto que se vende es la información y el entretenimiento. Se ha convertido en un rasgo característico del actual panorama económico mundial'12 (2006, p. 203).

Así, resulta claro que las corporaciones trasnacionales de medios forman parte de la CCT y como tal ejercen poder en el mundo globalizado. Sus operaciones, llevadas a cabo simultáneamente en diferentes países gracias al influjo de la tecnología digital, afectan a millones de personas, las audiencias trasnacionales, quienes acceden a las imágenes de mundo deseadas por sus propietarios, de acuerdo con sus intereses particulares (Appadurai, 1990).

Este carácter transnacional de las organizaciones de medios y de los productos que estas generan es una de las características de la comunicación de hoy y, por lo tanto, es necesario ubicarse en esta perspectiva de análisis para ampliar y profundizar en la reflexión sobre las dinámicas de formación y comportamiento de las audiencias.

Hoy la recepción de la comunicación se produce en un ambiente mediático marcado por la sobre oferta de contenidos locales e internacionales, por el desvanecimiento de las fronteras geográficas y el consecuente avance de los procesos de desterritorialización, en donde el concepto de nación va allende al de territorio, en el que la descodificación

12 Traducción de los autores. 
de los contenidos se realiza desde un repertorio de referentes semióticos y culturales ampliado, lleno de hibridaciones.

Hoy la recepción está atravesada por el consumo a través de múltiples plataformas, por la desestructuración de las parrillas de programación, que otrora determinaban los tiempos de las audiencias, por la deslocalización espacial del acto de recepción; en últimas, por la ampliación de facilidades para el acceso a los productos, lo cual impacta directamente en la autonomía de las audiencias, entendida esta como el grado de control que ellas tienen sobre sus interacciones con los medios.

Además, la recepción está determinada por los ya conocidos y comprobados procesos de fragmentación de audiencias que se vienen desarrollando a la par con la masificación de las tecnologías digitales. La fragmentación, entendida como otra de las características del escenario comunicativo de hoy, se define como la desintegración de las tradicionales audiencias masivas, lo cual implica una creciente importancia de escenarios de cola larga (C. Anderson, 2006). Tales escenarios consisten en que la atención de un mercado, o de una gran audiencia, se centra alrededor de una pequeña selección de opciones de productos o contenidos, llamados hits, pero al mismo tiempo se produce una larga cola de pequeñas audiencias que están interesadas en multitud de opciones de contenido que responden a sus preferencias personales particulares. Al final, la cola larga de opciones fragmentadas puede llegar a exceder en tamaño la audiencia de los hits. En otras palabras, se trata de un modelo basado en vender poco a muchos que tienen gustos particulares.

En el caso de los medios, se diría que la fragmentación implica ofrecer más contenidos, sobre la base de que existen audiencias que los van a consumir, pero en menor escala que en la comunicación masiva. Los procesos de digitalización y los avances en plataformas de distribución facilitan que este escenario se produzca a un costo relativamente bajo y a la vez abre la posibilidad de ampliar el mercado de la audiencia, pues da cabida a un mayor número de anunciantes interesados en ofrecer sus productos a estos grupos de población minoritarios, pero que se extienden más allá de las fronteras de una nación, es decir, a una audiencia trasnacional.

Así, queda en evidencia la estrecha relación existente entre la naturaleza trasnacional de las audiencias y su carácter autónomo y fragmentado, lo cual tiene implicaciones prácticas para los procesos de investigación y análisis que sobre ellas se realizan. Ya no es suficiente saber quiénes se exponen a un programa y por cuánto tiempo, entre otros motivos porque las medidas como el rating o el share nuevamente circunscriben la audiencia a un territorio nacional, llevándola a un estadio de comprensión anterior. Al pensar en la audiencia trasnacional es deseable que la investigación deje abordar cuestiones relacionadas con la razón por la cual algunos productos logran convocar audiencias en varias nacionales, mientras que otros siguen impactando solo en el ámbito local, cómo personas con diferentes procedencias geográficas y culturales dan sentido a un mismo producto, cómo algunos contenidos se constituyen en referentes culturales de alcance internacional y cómo afectan los procesos de formación de identidad y de vinculación con el mundo. Los retos epistemológicos y metodológicos quedan, entonces, abiertos. 


\section{Bibliografía}

Albarran, A., Chan-Olmstead, S., E Wirth, M. (2006). Handbook of Media Management and Economics. Mahwah, New Jersey: Lawrence Erlbaum Associates LEA.

Anderson, B. (1993). Comunidades Imaginadas. Mexico: FCE.

Anderson, C. (2006). The long tail: Why the future of business is selling less of more. New York: Hyperion.

Appadurai, A. (1990). disjuncture and difference in the global cultural economy. Theory Culture Society, 7, 295-310.

Castells, M. (2008). La era de la información: Economía, sociedad y cultura. La sociedad red. La era de la información: Economía, sociedad y cultura (Vol. 1, p. 656). Madrid: Alianza Editorial.

Chalaby, J. (2005). Transnational Television Worldwide. Towards a New Media Order. New York: I.B. Tauris \& Co. Ltd.

Donsbach, W. (2006). The identity of Communication Research. Journal of Communication, 56, 437-448.

Echeverría, J. (1999). Los señores del aire: Telépolis y el tercer entorno. Barcelona: Destino.

Ekwo, U. (2011). Diaspora Media and Citizen Engagement in the Digital Age: Analyzing the Impact of Transnational Journalism on Democratization. In Diaspora Strategies: Encouragement, Evolution, and Engagement. Dublin: The Clinton Institute of American Studies.

Faist, T. (2000). Transnationalization in International Migration: Implications for the Study of Citizenship and Culture. Ethnic and Racial Studies, 23(2), 189-222.

Garnham, N. (1983). Toward a Theory of Cultural Materialism. Journal of Communication, 33(3), 314-329.

Hopenhayn, M. (2001). Crítica de la razón irónica. De Sade a Jim Morrison. Buenos Aires: Editorial Sudamericana.

Jenkins, H., Ford, S., E Green, J. (2013). Spreadable media: Creating value and meaning in a networked culture. (H. Jenkins, Ed.)Vasa (First.). New York: New York University Press. Retrieved from http:// medcontent.metapress.com/index/A65RM03P4874243N.pdf

Jenkis, H. (2006). Convergence Culture. La cultura de la convergencia de los medios de comunicación. Barcelona: Paidós.

Kearney, M. (1995). The Local and the Global: The Anthropology of Globalization and Transnationalism. Annual Review of Anthropology., 24, 547-565.

Maffesoli, M. (2005). El nomadismo. Vagabundeos iniciáticos. Mexico: FCE.

Martín-Barbero, J. (1995). Dinámicas urbanas de la cultura. In Comunicación y espacios culturales en América Latina. Bogotá: Cátedra UNESCO - PUJ.

McQuail, D. (2010). Mass Communication Theory (6th ed.). London: Sage.

Moreno, G. (2009). Transnational audiences and the reception of television news: a study of Mexicans in Los Angeles. University of Westminster.

Moreno, G. (2010). Mexicanos en Los Ángeles: audiencia transnacional y noticias de televisión. Comunicación Y Sociedad, 14, 49-82.

Morley, D. (1996). Televisión, Audiencias y Estudios Culturales. Buenos Aires: Amorrortu. 
Müller-Mahn, D. (2005). Transnational spaces and migrant networks: A case study of Egyptians in Paris. Nord Süd Aktuell, 1, 29-33.

Napoli, P. M. (2001). The Audience Product and the New Media Environment: Implications for the Economics of Media Industry. Journal of Media Management., Vol. 3 No, 66-73.

Orozco, G. (2008). Audiencias y pantallas. Lo nuevo, lo viejo y lo que viene. Lima: Pontificia Universidad Católica de Perú. Retrieved from http://revistas.pucp.edu.pe/lamiradadetelemo/audienciasy-pantallas

Picard, R. (2011). Mapping Digital Media: Digitization and Media Business Models. (M. Dragomir \& M. Thompson, Eds.). London: Open Society Fundations.

Sinclair, J. (2000). Televisión: Comunicación Global y Regionalización. Barcelona: Gedisa.

Sklair, L. (2002). Democracy and the Transnational Capitalist Class. The Annals of the American Academy, 581, 144-157.

Virilio, P. (1999). El cibermundo la politica de lo peor. Madrid: Cátedra. 